\title{
Pathways of Processing of the Gastrin Precursor in Rat Antral Mucosa
}

\author{
A. Varro, S. Voronina, and G. J. Dockray \\ Physiological Laboratory, University of Liverpool, Liverpool, L69 3BX United Kingdom
}

\begin{abstract}
The precursor of the acid-stimulating hormone gastrin gives rise to multiple peptides differing markedly in biological activity, but the relevant biosynthetic pathways are poorly understood. We have used antibodies to amidated gastrins, gastrins with COOH-terminal glycine (Gly) gastrins with COOH-terminal hydroxyglycine (GlyOH) and to the $\mathrm{COOH}$ terminus of progastrin, to immunoprecipitate peptides labeled with $\left[{ }^{35} \mathrm{~S}\right]$ sulfate or $\left[{ }^{3} \mathrm{H}\right]$ tyrosine during incubation of rat antral mucosa in vitro. Labeled progastrin was detectable after 30 min of continuous incubation with isotopic precursors, G34 and G34-Gly after $60 \mathrm{~min}$, and G17 and G17-Gly after 120 min. Pulse chase experiments indicated that progastrin is converted to G34-Gly which then follows one of two pathways: $(a)$ hydroxylation of COOH-terminal Gly and conversion to G34 followed by cleavage yielding G17, or (b) cleavage to G17-Gly. The kinetics of G17-Gly and G17 labeling were similar, suggesting that G17-Gly is a product in its own right, and not simply an intermediate in G17 synthesis. Since the two peptides are reported to have distinct biological activities, they appear to be alternative mature products of progastrin processing. (J. Clin. Invest. 1995. 95:1642-1649.) Key words: biosynthesis • posttranslational processing $\bullet$ amidation $\cdot$ gastrin
\end{abstract}

\section{Introduction}

The production of biologically active hormonal and neurotransmitter peptides generally requires multiple posttranslational modifications of a large, usually inactive, precursor. Common processing steps include cleavage of the peptide chain at pairs of basic residues, tyrosine sulfation, serine phosphorylation, and $\mathrm{COOH}$-terminal amidation $(1,2)$. In the precursor of the acidstimulating hormone gastrin, all of these processing events occur in a decapeptide sequence that includes the shortest fragment able to stimulate acid secretion (3). Previous studies have identified a wide variety of different peptides derived from progastrin, the best characterized of which are the COOH-terminally amidated peptides, G17 and G34 (4-7).

It has been recognized for many years that G17 and G34 have similar potencies for stimulation of acid secretion, but differ markedly in metabolic clearance rates $(8-10)$. They are

Address correspondence to G. J. Dockray, Physiological Laboratory, University of Liverpool, Crown Street, P. O. Box 147, Liverpool, L69 3BX, United Kingdom. Phone: 51-794-5324; FAX: 51-794-5315.

Received for publication 8 August 1994 and in revised form 15 November 1994.

J. Clin. Invest.

(C) The American Society for Clinical Investigation, Inc. 0021-9738/95/04/1642/08 \$2.00

Volume 95, April 1995, 1642-1649 both found in the human circulation after a meal, although it is thought that G17 is mainly of antral origin and G34 of duodenal origin (11). These peptides are generally considered to be the primary active products of the gastrin precursor. However, recent reports indicate that gastrins extended at the $\mathrm{COOH}$ terminus by glycine also have biological actions, notably growth promoting effects on the AR4-2J cell line and stimulation of $\mathrm{H}^{+} / \mathrm{K}^{+}$ATPase $\alpha$-subunit gene expression, that are distinct from those of the amidated gastrins and appear to be mediated by novel receptors $(12-14)$. Peptides terminating in gastrins with $\mathrm{COOH}$-terminal glycine (-Gly) ${ }^{1}$ are converted to $\mathrm{COOH}$ terminally amidated peptides by the enzyme, peptidyl $\alpha$-amidating mono-oxygenase (PAM) (15). Several groups have identified naturally occurring Gly-extended gastrins (16-19), and have suggested that these peptides are intermediates in the synthesis of the amidated product (Fig. 1). However, there have been no direct studies of the biosynthetic relationships between progastrin-derived peptides, and consequently it is not clear whether there are separate and distinctive biosynthetic routes leading to production of -Gly extended, and amidated gastrins. In the present study we have examined the pathways of processing of progastrin in rat antrum. The data suggest that progastrin is converted to G34-Gly, which is then processed either to G34-GlyOH (gastrins with COOH-terminal hydroxyglycine), G34 and then G17, or to G17-Gly. The kinetics of production of G17 and G17-Gly are closely similar, suggesting that they should both be considered as mature active products, and consequently that a common sequence of progastrin gives rise to either of two types of distinct active peptide.

\section{Methods}

Labeling experiments. The biosynthesis of progastrin-derived peptides was studied by following incorporation of $\left[{ }^{35} \mathrm{~S}\right]$ sulfate and $\left[{ }^{3} \mathrm{H}\right]$ tyrosine in rat antral mucosa incubated in vitro as previously described $(20,21)$. Briefly, antral mucosal segments were incubated at $37^{\circ} \mathrm{C}$ in a modified Krebs-Ringer biocarbonate medium supplemented with amino acids and vitamins, and gassed with $95 \% \mathrm{O}_{2}$ and $5 \% \mathrm{CO}_{2}$. Medium contained 50 $\mu \mathrm{Ci} / \mathrm{ml}\left[{ }^{3} \mathrm{H}\right.$ ] Tyr and 100 or $200 \mu \mathrm{Ci} / \mathrm{ml}\left[{ }^{35} \mathrm{~S}\right.$ ] sulfate (both obtained from Amersham International, Buckinghamshire, United Kingdom), and omitted unlabeled sulfate or tyrosine except in chase experiments. Two experimental protocols were used. First, the pattern of labeling of progastrin-derived peptides was examined during continuous incubation with isotopic precursors for periods of $30 \mathrm{~min}$ to $4 \mathrm{~h}$. Second, the kinetics of interconversion of different progastrin-derived peptides were examined in pulse-chase experiments. Pulse-labeling of progastrin was produced by incubation at $22^{\circ} \mathrm{C}$ for $2 \mathrm{~h}$; previous studies have established that this leads to accumulation of radiolabeled progastrin in the terminal regions of the Golgi complex (21). Chase experiments were then carried out in medium containing unlabeled tyrosine and sulfate at $37^{\circ} \mathrm{C}$; samples of tissue and media were taken at 10-160 min during the chase.

1. Abbreviations used in this paper: $\mathrm{CFP}, \mathrm{COOH}$-terminal tryptic fragment of progastrin; -Gly, gastrins with $\mathrm{COOH}$-terminal glycine; -GlyOH, gastrins with $\mathrm{COOH}$-terminal hydroxyglycine, PAM, peptidyl $\alpha$-amidating mono-oxygenase. 

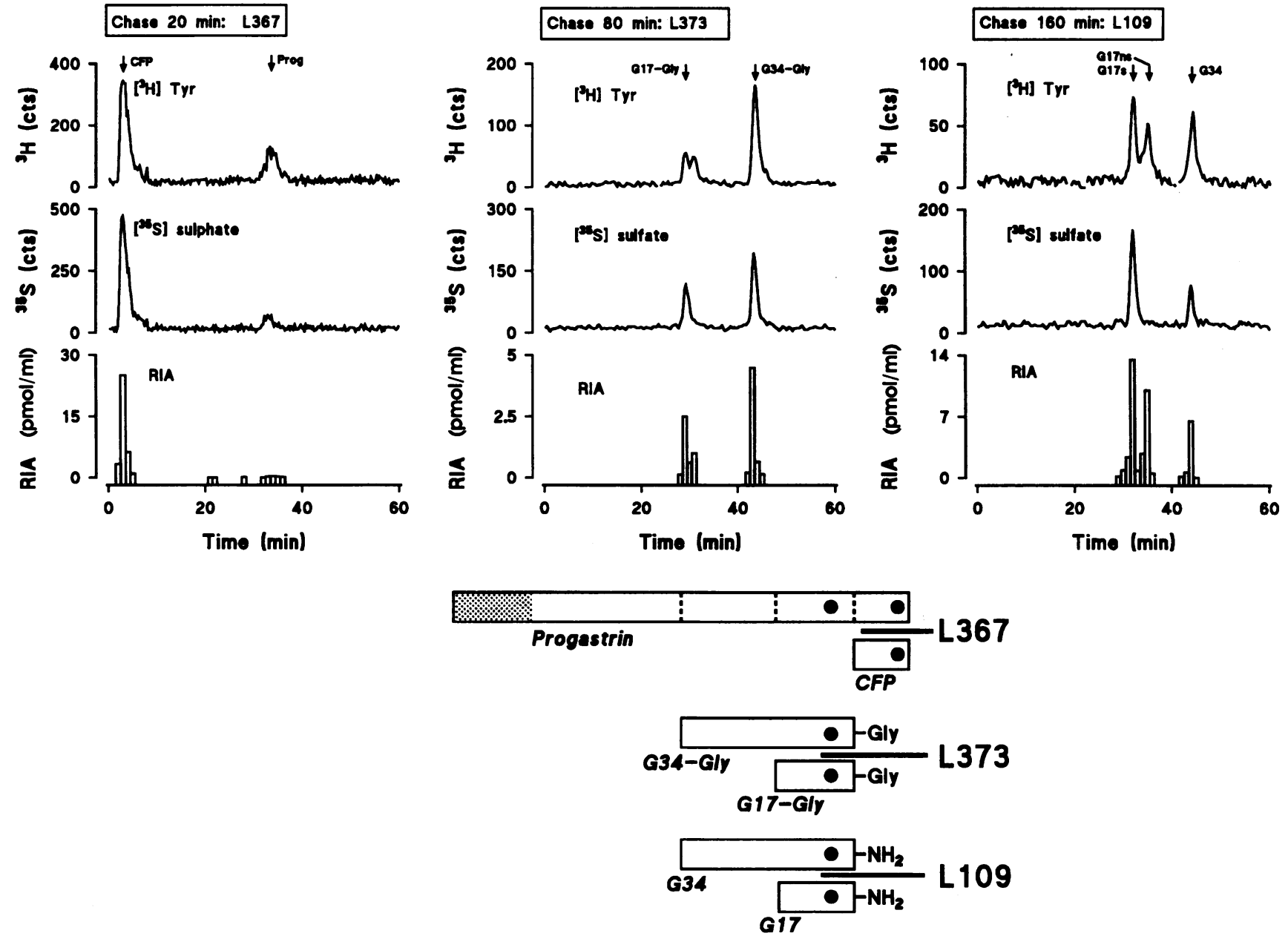

Figure 1. Schematic representation of progastrin and its major products, antibodies used for precipitation, and typical HPLC separations. Bottom shows the relationships between progastrin, the two main Gly-extended products (G34-Gly and G17-Gly), and the two main amidated peptides (G34 and G17). The labeling sites, i.e., sulfated tyrosines, are indicated by filled circles; note, these are the only tyrosines in rat progastrin. Horizontal bars show the specificity of antibodies used for immunoprecipitation: L367 (COOH terminus progastrin), L373 (Gly-extended gastrins), and L109 (amidated gastrins). Not shown here are -GlyOH peptides produced as an intermediate in the amidation reaction. Top, left shows a representative HPLC result of fractionation of a sample precipitated with L367 after 20-min chase. Samples were applied to columns equilibrated in 50-mM ammonium bicarbonate and eluted with a gradient to $28 \%$ acetonitrile over $28 \mathrm{~min}$, which progressed to $50 \%$ from 46 to $56 \mathrm{~min}$. The main labeled peak corresponds to the CFP and there is a small peak corresponding to progastrin. Note that radioimmunoassay (RIA) shows a major peak of CFP and minor peaks corresponding to progastrin and larger COOH-terminal fragments. Top, center, HPLC profile after separation of a sample precipitated with $\mathrm{L} 373$ after 80 -min chase. The elution system was similar to that already described except that a gradient to $16 \%$ acetonitrile was run over $16 \mathrm{~min}$ and then to $50 \%$ acetonitrile. There are peaks of label, and of immunoreactivity corresponding to G34-Gly and G17-Gly. There is only partial separation of sulfated and unsulfated G17-Gly and no separation of sulfated and unsulfated G34-Gly. Top, right, HPLC profile of a sample precipitated with L109, after 160-min chase. Gradient was identical to that used for L373 immunoprecipitates. There are peaks of label, and immunoreactivity, corresponding to G34, and G17. The sulfated and unsulfated forms of the latter, but not the former, are separated. cts, counts per update period $(15 \mathrm{~s})$.

Extraction of progastrin-derived peptides. Following incubation, tissue and media were separated. Tissues samples were routinely washed in ice-cold medium, boiled in $1 \mathrm{ml}$ water, homogenized, and centrifuged $(10,000 \mathrm{~g}, 1 \mathrm{~min})$. The supernatant was recovered, and the pellet washed with a further $1 \mathrm{ml}$ water, centrifuged, and the supernatants combined. Progastrin and its derivatives in media or tissue extracts were then concentrated as previously described (21). Briefly, samples were concentrated on C18 cartridges (Sep-pak; Waters Associates, Millipore Corp., Milford, MA) and eluted with $50 \%$ acetonitrile in $0.02 \mathrm{M}$ phosphate buffer $\mathrm{pH} 7.2$; acetonitrile was subsequently removed in a stream of $\mathrm{N}_{2}$. Progastrin-derived peptides that were not retained by $\mathrm{C} 18 \mathrm{car}-$ tridges (mainly $\mathrm{COOH}$-terminal flanking peptide of progastrin, $\mathrm{COOH}$ terminal tryptic fragment of progastrin [CFP]) were diluted with 4 vol isopropanol and concentrated on Sep-pak Silica cartridges as previously described (22); this material was eluted with $0.02 \mathrm{M}$ phosphate buffer, lyophilized, re-dissolved in $1.5 \mathrm{ml}$ water, and combined with the $\mathrm{C} 18$ eluates for immunoprecipitation.

Immunoprecipitation. Radio-labeled progastrin-derived peptides were purified by immunoprecipitation using four different types of antibody. Routinely, samples were precipitated in turn with antibodies to (a) the $\mathrm{COOH}$ terminus of progastrin (L367) which recovers progastrin and $\mathrm{COOH}$-terminal fragments, including CFP, $(b)$ Gly-extended gastrins (L373), and (c) COOH-terminally amidated gastrins (L109) (Fig. 1). In each case, $50 \mu \mathrm{l}$ of antiserum was added to the sample in $2 \mathrm{ml}$ $0.02 \mathrm{M}$ phosphate buffer $\mathrm{pH} 7.4$, containing $15 \mu \mathrm{l}$ liquid BSA (stock $22 \% \mathrm{vol} / \mathrm{vol}$, Advanced Protein Products Ltd., Brierly Hill, West Mid- 
lands, United Kingdom) together with $200 \mu$ l goat anti-rabbit precipitating antibody (Incstar Corp., Stillwater, MN). Precipitates were allowed to form at $4^{\circ} \mathrm{C}$ overnight and were recovered by centrifuging at 3,000 $g$ for $10 \mathrm{~min}$. Precipitates were washed five times by resuspension in 3 $\mathrm{ml} 0.02 \mathrm{M}$ phosphate buffer $\mathrm{pH} 7.4$, containing $0.75 \% \mathrm{vol} / \mathrm{vol}$ liquid BSA, and after the final wash were solubilized by boiling in $1 \mathrm{ml}$ water. The supernatant from the first precipitation was briefly boiled to denature any remaining immunoglobulin, cooled, and then taken for precipitation with the next antibody. Pilot experiments showed that similar patterns of recovery were obtained regardless of the order in which antibodies were used in serial precipitations. The specificity of the antibodies used for precipitation was verified by radioimmunoassay of solubilized precipitates. Thus, for example, antibody L109 precipitated immunoreactive amidated gastrins, but not peptides detected in radioimmunoassay (see below) for progastrin or -Gly-extended gastrins.

The antibody specific for the $\mathrm{COOH}$ terminus of progastrin has previously been described in detail $(20,21)$. Rabbit antibody specific for the $\mathrm{COOH}$ terminus of Gly-extended gastrins was raised by immunization with Gly-extended COOH-terminal nonapeptide of G17 (G9Gly) coupled to thyroglobulin with glutaraldehyde as previously described (23). Antibody specific for the $\mathrm{COOH}$ terminus of amidated gastrins was raised to the terminal tetrapeptide amide coupled to thyroglobulin as described (24). In all three cases bleedings taken after the second immunization were found to be the most useful for immunoprecipitation.

HPLC. Solubilized immunoprecipitates were clarified by centrifugation at $100,000 \mathrm{~g}$ and fractionated by reversed phase HPLC using an Altex system with on-line scintillation counting using a Radiomatic detection system (Canberra-Packard, Pangbourne, United Kingdom) and UltimaFlo AP scintillation cocktail (Canberra-Packard). Samples were applied routinely to $4.6 \times 150 \mathrm{~mm}$ columns of $8 \mu$ PLRP-S (Polymer Laboratories, Church Stretton, United Kingdom) equilibrated with 0.05 M ammonium biocarbonate, and eluted with a gradient of acetonitrile (see figure legends for details); but for separations of -GlyOH labeled gastrins, the aqueous phase was $20 \mathrm{mM}$ Tris, $\mathrm{pH}$ 7.4. The flow rate was $1 \mathrm{ml} / \mathrm{min}$, and the update time for counting was $15 \mathrm{~s}$. In control separations, a spillover of $30 \%$ of ${ }^{35} \mathrm{~S}$ counts into the ${ }^{3} \mathrm{H}$ channel was found, and all data were corrected for this. In some experiments, column eluates were split to provide a sample for radioimmunoassay, and in these cases the counts obtained were corrected for the split-fraction.

Radioimmunoassay. Progastrin and its $\mathrm{COOH}$-terminal fragments in HPLC eluates was detected by radioimmunoassay using antibody L363 (21). A mouse monoclonal antibody (mAb 109-21, generously provided by Dr. J. H. Walsh, University of California at Los Angeles) was used to assay Gly-extended gastrins (18) and antibody L2 was used to assay amidated gastrins (25).

Gastrins terminating in hydroxyglycine (i.e., -GlyOH) were sought using antibody (L394) raised to G9-GlyOH. Peptide in the form of the mixed enantiomers of G9-GlyOH $(740 \mathrm{nmol})$ was conjugated to thyroglobulin $(2 \mathrm{mg}$ ) in $1.0 \mathrm{ml} 0.1 \mathrm{M}$ phosphate buffer $\mathrm{pH} 7.4$ by addition of glutaraldehyde $(50 \mu \mathrm{l})$. The product was dialyzed overnight against 4 liters distilled water and emulsified in Freund's complete adjuvant for immunization of four rabbits ( $50 \mathrm{nmol}$ equivalent); rabbits were boosted at 6-wk intervals and bleedings taken 7-10 d later. For radioimmunoassays, G9-GlyOH was radiolabeled with ${ }^{125} \mathrm{I}$ using iodogen and the products purified by HPLC. Radioimmunoassay incubations were made in $1 \mathrm{ml} 0.02 \mathrm{M}$ phosphate buffer $\mathrm{pH} 7.4$ containing $0.75 \%$ $\mathrm{vol} / \mathrm{vol}$ liquid BSA, for $48 \mathrm{~h}$ at $4^{\circ} \mathrm{C}$ and separated by addition of 200 $\mu \mathrm{l}$ of a suspension of charcoal $(100 \mathrm{~g} / \mathrm{liter})$ coated with dextran (10 g) and fat-free milk powder $(5 \mathrm{~g})$. The specificity of the assay was determined by comparison of inhibition of binding of label by the mixed enantiomers of G9-GlyOH, G17, G9-Gly, mixed enantiomers of CCK8$\mathrm{GlyOH}$, the separate enantiomers of G4-GlyOH, G4-Gly, and G4.

Stability of - GlyOH peptides. The stability of -GlyOH-modified gastrins was determined by incubation at $4^{\circ}, 22^{\circ}$, or $37^{\circ} \mathrm{C}$ of the mixed enantiomers of G4-GlyOH $(6.7 \mathrm{nmol} / \mathrm{ml})$ in $0.05 \mathrm{M}$ phosphate buffer at pH 6.0,7.4, or 8.0 , for up to $8 \mathrm{~d}$. Aliquots were separated by HPLC on a Vydac C18 (protein and peptide) column, using $16 \%$ acetonitrile

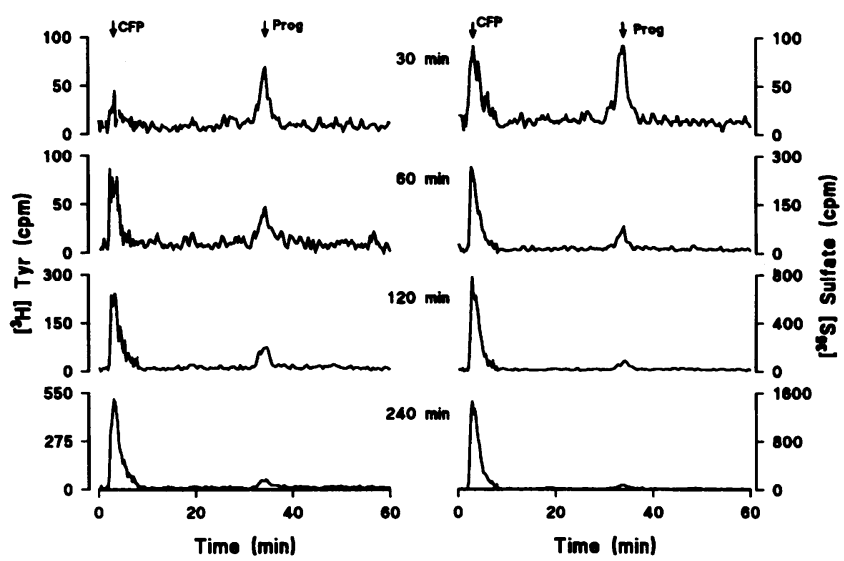

Figure 2. Pattern of labeling of progastrin and its $\mathrm{COOH}$-terminal fragments during continuous incubation at $37^{\circ} \mathrm{C}$. In this and similar subsequent figures, left panel, shows incorporation of $\left[{ }^{3} \mathrm{H}\right] \mathrm{Tyr}$ and right panel shows incorporation of $\left[{ }^{35} \mathrm{~S}\right]$ sulfate. See Fig. 1 for details of the gradient used for elution. After 30-min incubation there is incorporation into progastrin, and with longer incubation, there is a progressive increase in labeled CFP (note the different scales for ordinates).

and $84 \%$ trifluoroacetic acid $(0.1 \% \mathrm{vol} / \mathrm{vol})$. This system separates the two stereo-enantiomers of G4-GlyOH, from G4-Gly and G4. The latter was detected by absorbance at $280 \mathrm{~nm}$ and determined by radioimmunoassay using antibody to G4 (24).

\section{Results}

Time course of production of new gastrin. Continuous incubation of rat antral mucosal segments at $37^{\circ} \mathrm{C}$ with $\left[{ }^{3} \mathrm{H}\right] \mathrm{Tyr}$ and $\left[{ }^{35} \mathrm{~S}\right]$ sulfate was associated with linear incorporation of both labels into progastrin-derived peptides. Labeled progastrin was identified within $30 \mathrm{~min}$ of starting the incubation; the relative magnitude of the labeled progastrin peak did not change thereafter, but there was a progressive increase in the labeling of its COOH-terminal tryptic fragment (Fig. 2). At the earliest time point studied (30 $\mathrm{min}$ ) the labeling of the latter was greater with $\left[{ }^{35} \mathrm{~S}\right]$ sulfate than $\left[{ }^{3} \mathrm{H}\right] \mathrm{Tyr}$, which is compatible with the incorporation of sulfate at the trans-Golgi network (21), and of amino acids into newly translated peptide in endoplasmic reticulum (Fig. 2).

A small peak of $\left[{ }^{35} \mathrm{~S}\right] \mathrm{G} 34-\mathrm{Gly}$ was seen within $30 \mathrm{~min}$ of starting the incubation (Fig. 3). The appearance of $\left[{ }^{35} \mathrm{~S}\right] \mathrm{G} 34-$ Gly preceded that of $\left[{ }^{3} \mathrm{H}\right] \mathrm{G} 34-G l y$ which was first identified after $60 \mathrm{~min}$. Moreover, $\left[{ }^{35} \mathrm{~S}\right] \mathrm{G} 34-\mathrm{Gly}$ also appeared earlier than $\left[{ }^{35}\right.$ S $]$ G34. Labeled G17-Gly and G17 first appeared at 120 min, and the relative magnitude of these peaks increased with continued incubation (Fig. 3).

Pulse-chase experiments. The results described above provide information on the time taken to generate newly synthesized gastrins, but provide relatively little information on the pathways of posttranslational processing. To address this issue we used a pulse-chase protocol that made of use of the fact that at $22^{\circ} \mathrm{C}$ progastrin is labeled with both $\left[{ }^{35} \mathrm{~S}\right]$ sulfate and $\left[{ }^{3} \mathrm{H}\right]-$ Tyr, and accumulates in the terminal regions of the Golgi complex (21). Further progression of progastrin along the secretory pathway occurs rapidly on raising the temperature to $37^{\circ} \mathrm{C}$; in the present experiments, the transfer of samples from 22 to $37^{\circ} \mathrm{C}$ was timed to coincide with the start of the chase period. The 

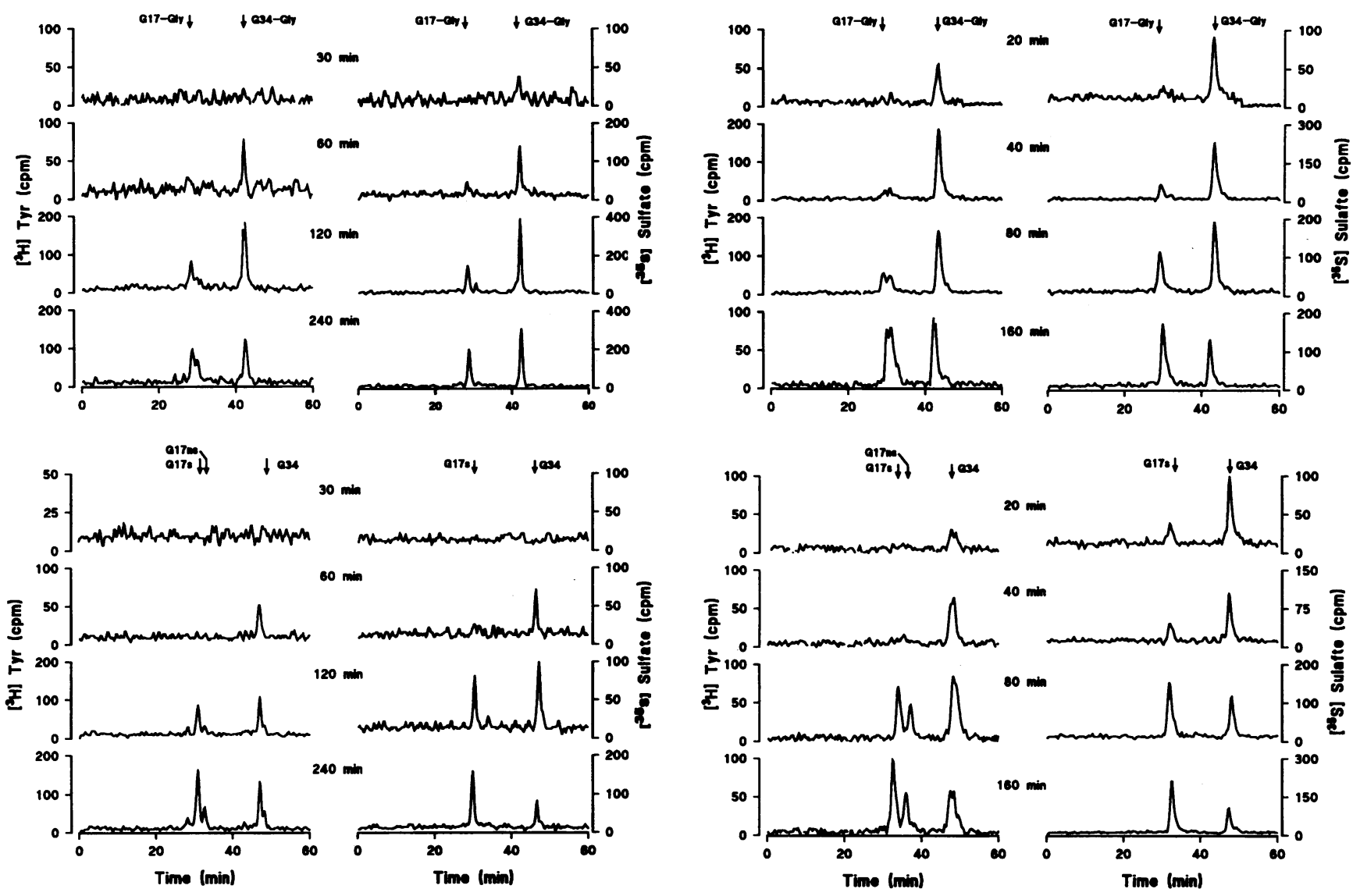

Figure 3. Labeling of -Gly-extended and amidated gastrins during continuous incubation at $37^{\circ} \mathrm{C}$ with $\left[{ }^{3} \mathrm{H}\right] \mathrm{Tyr}$ and $\left[{ }^{35} \mathrm{~S}\right]$ sulfate. Top, HPLC separation of precipitates using antibody to -Gly-extended gastrins. Bottom, HPLC separation of precipitates using antibody to amidated gastrins. Note G34-Gly and G34 appear before G17-Gly and G17. The latter predominates by $240 \mathrm{~min}$. See Figs. 1 and 2 for further information.

labeled progastrin-derived peptide which appeared earliest in chase experiments was G34-Gly (Fig. 4). The magnitude of the peak of labeled G34-Gly was maximal after 20-40 min, and thereafter there was a progressive decline (Fig. 5). A clearly identifiable peak of labeled G34 was already evident after 20 min, was maximal at $40-80 \mathrm{~min}$, and then declined. Thus, the appearance of G34 was somewhat delayed compared with G34Gly, but in both cases, and with both isotopes, there was a decline in the labeled material from 80 to $160 \mathrm{~min}$ of the chase (Figs. 4 and 5).

Clearly defined peaks of labeled G17-Gly and G17 were found after $80 \mathrm{~min}$ chase, but unlike the labeling of G34-Gly, or G34, these peaks then increased further up to $160 \mathrm{~min}$ of chase (Figs. 4 and 5). By 160 min, labeled G17 and G17-Gly were the predominant material identified in immunoprecipitates with L109 and L373, respectively. Thus the time course of labeling of G17-Gly and G17 was similar, and the appearance of these peptides coincided with decreases in G34-Gly and G34. The pattern of labeling with $\left[{ }^{35} \mathrm{~S}\right]$ sulfate was closely similar to that with $\left[{ }^{3} \mathrm{H}\right] \mathrm{Tyr}$ which labels both sulfated and unsulfated peptides except that sulfated peptides appeared slightly earlier for reasons noted above. These data suggest that amidation is not influenced by sulfation at $\mathrm{Tyr}^{87}$. In support of this, the

Figure 4. Labeling of -Gly-extended and amidated gastrins in a pulsechase experiment. Pulse labeling was conducted at $22^{\circ} \mathrm{C}$ for $120 \mathrm{~min}$; chases were conducted at $37^{\circ} \mathrm{C}$. Note the early appearance of G34-Gly and G34, followed by G17-Gly and G17. See Figs. 1-3 for further details.

data in Fig. 4 show clearly resolved peaks of $\left[{ }^{3} \mathrm{H}\right]$ Tyr-labeled unsulfated and sulfated G17, which exhibit similar labeling kinetics (Fig. 4). Moreover in other experiments using HPLC systems that separate the sulfated and unsulfated forms of G34, G34Gly, and G17-Gly, there were also similar labeling kinetics (results not shown).

Secretion of labeled progastrin-derived peptides. A decrease in cellular content of total amidated and -Gly extended gastrins labeled with both $\left[{ }^{35} \mathrm{~S}\right]$ sulfate and $\left[{ }^{3} \mathrm{H}\right] \mathrm{Tyr}$ occurred from 80 to $160 \mathrm{~min}$ in chase experiments (Fig. 5, left). This might be due to secretion into the media, and to provide further information on this point, secreted labeled gastrins were directly identified by immunoprecipitation of media at intervals during the chase period. Antibodies to both amidated and -Gly-extended gastrins failed to reveal labeled peptides in the media at chase times of 10-40 min, and at $80 \mathrm{~min}$, labeled gastrins were not reproducibly identified. However, at a chase time of 160 min there was both labeled amidated and -Gly-extended gastrins in the media, indicating that the two forms are secreted in parallel. The predominant amidated peptide was G17, and there was a small amount of poorly resolved material corresponding to G34; well resolved peaks corresponding to both G34-Gly and G17-Gly were detected in the media (Fig. 6).

Identification of -GlyOH peptides. The data obtained by pulse-chase experiments indicate that G34-Gly is converted to 

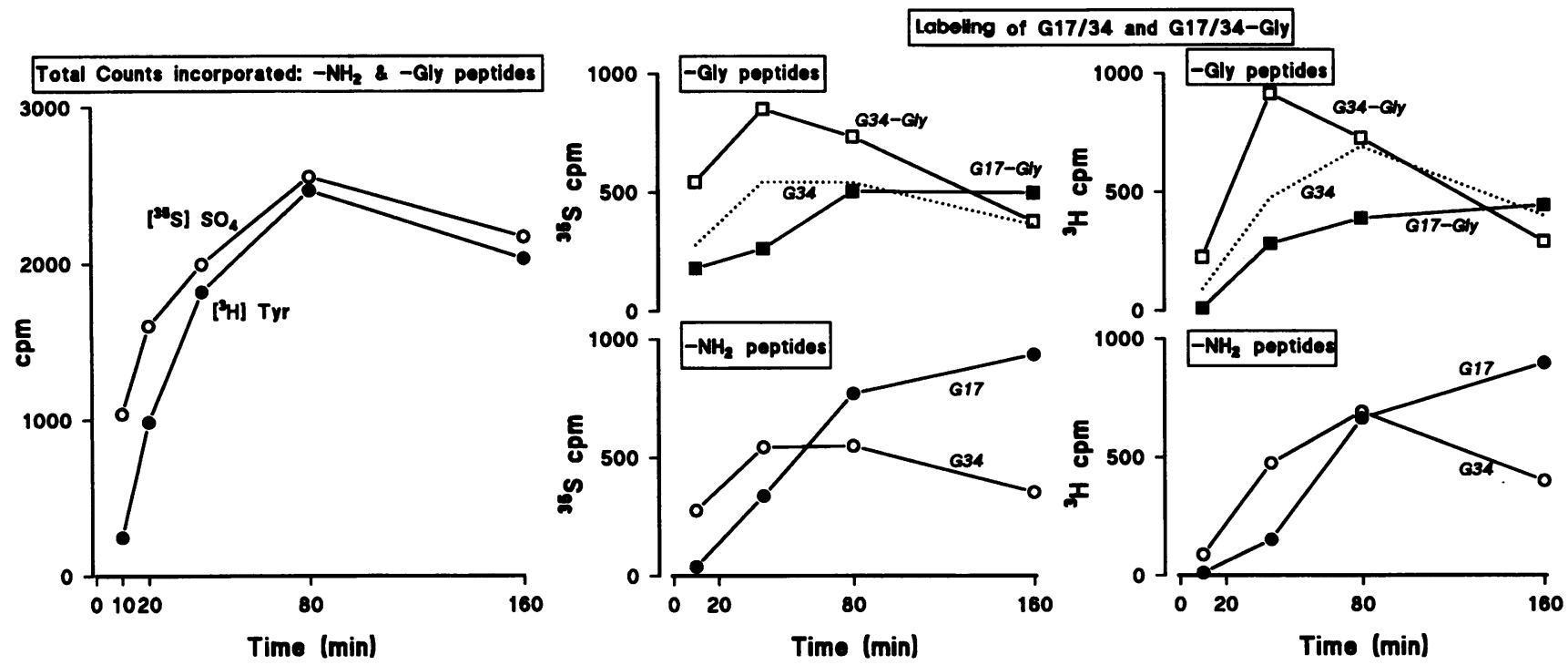

Figure 5. Kinetics of labeling of different progastrin-derived peptides in pulse-chase experiments. (Left) The total counts incorporated into -Gly and amidated gastrins. Note the slightly earlier appearance of sulfated peptides. (Center) Labeling with [ $\left.{ }^{35} \mathrm{~S}\right]$ sulfate of G34-Gly and G17-Gly (top) and G34 and G17 (bottom). For reference the pattern of labeling of G34 is also shown as a broken line in the top panel. (Right) Similar data for $\left[{ }^{3} \mathrm{H}\right]$ Tyr labeling. Note, the decline in G34-Gly and G34 after 40-80 min, and increase in G17-Gly and G17 up to 160 min. Mean data, from four experiments.

G34. It is believed that this conversion proceeds via the formation of a hydroxyglycine intermediate (15). Although the rearrangement of -GlyOH to the corresponding COOH-terminal amide is enzymically mediated, this step can also occur spontaneously. To characterize the production of amidated gastrins we sought -GlyOH intermediates, and as first towards this end we investigated the stability of G4-GlyOH with respect to $\mathrm{pH}$ and temperature. At $\mathrm{pH} 8.0$ and $37^{\circ} \mathrm{C}$ there was progressive conversion of G4-GlyOH to G4, in vitro (Fig. 7). Conversion was inhibited at $22^{\circ} \mathrm{C}$, and at $\mathrm{pH} 7.4$; it was virtually abolished at $4^{\circ} \mathrm{C}$ and at $\mathrm{pH} 6.0$.

The relative stability of $-\mathrm{GlyOH}$ at physiological $\mathrm{pH}$ sug-

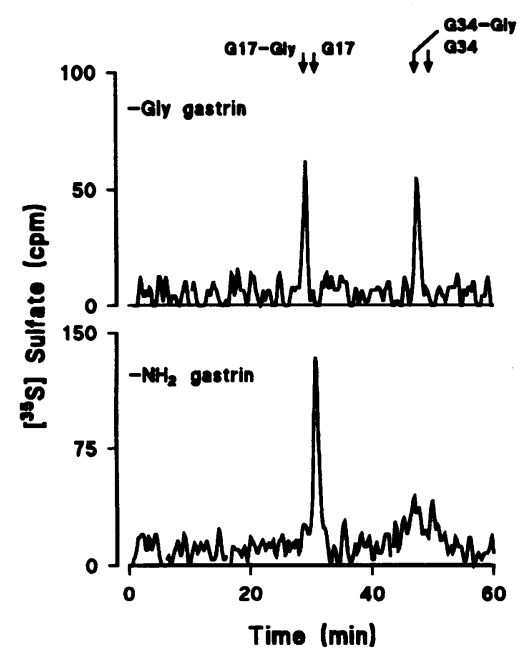

Figure 6. Secretion of amidated and -Gly-extended gastrins into the media. After pulse labeling with $200 \mu \mathrm{Ci} / \mathrm{ml}$ $\left[{ }^{35} \mathrm{~S}\right]$ sulfate for $2 \mathrm{~h}$ at $22^{\circ} \mathrm{C}$, samples were chased at $37^{\circ} \mathrm{C}$ for $10-$ $160 \mathrm{~min}$ and media sequentially precipitated with L109 and L373 to recover secreted peptides. Labeled secreted peptides were detected in samples at $160 \mathrm{~min}$, but not at 10-80 $\mathrm{min}$. Top, HPLC separation of labeled -Gly-extended gastrins, and bottom, HPLC separation of amidated gastrins from media after chasing for $160 \mathrm{~min}$. See Fig. 1 for further details. gested that it would be worth immunizing rabbits in an attempt to obtain specific antibodies. Four rabbits were immunized with a mixture of the two stereoenantiomers of G9-GlyOH; all four produced antibodies that bound ${ }^{125}$ I-labeled G9-GlyOH. The antiserum with the highest titer and affinity was selected for use in radioimmunoassay. The results of competitive binding experiments, indicated that radioimmunoassays using antibodies to -GlyOH gastrins showed about 10-fold higher affinity for these peptides compared with the corresponding -Gly-extended and amidated gastrins (Fig. 8). The immunoreactivity of cholecystokinin (CCK)-GlyOH was $\sim 30$-fold lower affinity than that of G9-GlyOH, and there was an $\sim 100$-fold difference in immunoreactivity between G9-GlyOH and G4-GlyOH. The two
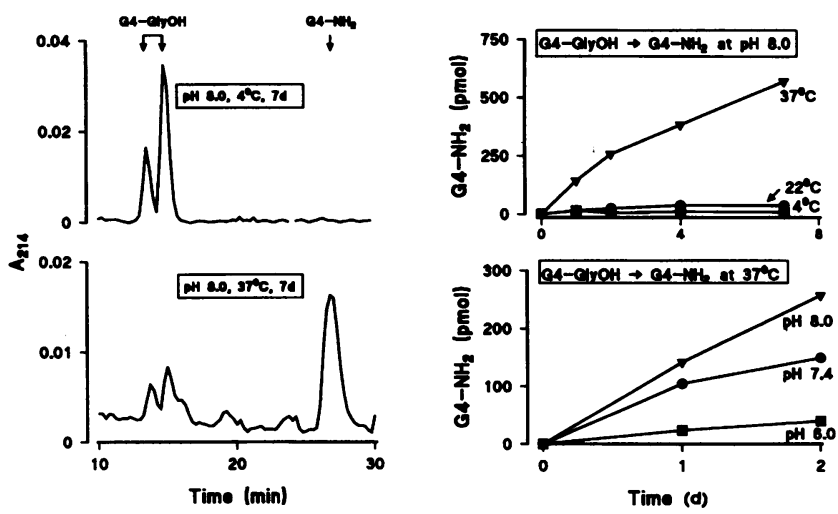

Figure 7. Stability of G4-GlyOH. Synthetic G4-GlyOH was incubated at $\mathrm{pH} 6.0-8.0$ and $4-37^{\circ} \mathrm{C}$, for varying periods of time and the products separated (left) by isocratic HPLC ( $16 \%$ acetonitrile in $0.1 \% \mathrm{vol} / \mathrm{vol}$ trifluoroacetic acid). In control experiments, it was possible to resolve two stereoenantiomers of G4-GlyOH. Both eluted well before G4, or G4Gly. Conversion of G4-GlyOH to G4 was most rapid at $\mathrm{pH} 8.0$ (bottom right) and $37^{\circ} \mathrm{C}$ (top right). 


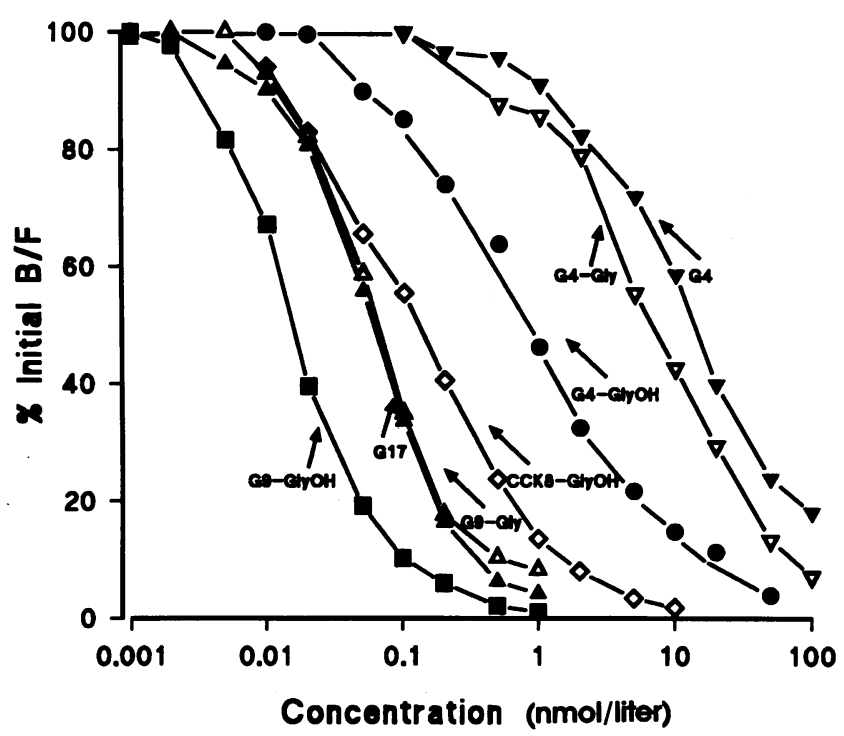

Figure 8. Radioimmunoassay dilution curves of -GlyOH gastrins, and related peptides, with an antibody raised to G9-GlyOH. The antibody shows 10-fold higher affinity for G9-GlyOH than G9-Gly or G17, and progressively lower affinity for cholecystokinin (CCK) 8-GlyOH and G4-GlyOH. Mixed stereoenantiomers of the -GlyOH peptides were used; reversed phase HPLC separated the two G4-GlyOH peptides, which reacted equally in radioimmunoassay. $\mathrm{B} / \mathrm{F}$, ratio of antibody bound to free radiolabeled peptide.

stereoisomers of G4-GlyOH were relatively readily separated by reversed phase HPLC (Fig. 7), and both were found to react equally in radioimmunoassay.

When antisera raised against G9-GlyOH were used in immunoprecipitation, peptides corresponding to labeled -Gly and amidated gastrins were recovered, in addition to putative -GlyOH gastrins. To demonstrate unequivocally the synthesis of -GlyOH gastrins, we sequentially precipitated samples with antibodies selective for -Gly-extended and amidated gastrins, before precipitation using the antibody to - GlyOH peptides. When this approach was applied to samples from a 20 -min chase, sequential precipitation with the appropriate antibodies recovered material corresponding to G34-Gly and a small peak of G34 (Fig. 9); the efficiency of these precipitation steps were established by reprecipitation with the same antibodies, when no further labeled material was recovered. Subsequent precipitation with antibody to -GlyOH gastrins then recovered a single peak of labeled material eluting slightly later than G34 (Fig. 9). Radioimmunoassay of the column eluates with antibody reacting with -GlyOH peptides, revealed two peaks of immunoreactivity one of which coincided with ${ }^{35} \mathrm{~S}$-labeled peptide, and neither of which coincided with a clear peak of immunoreactivity in assays specific for amidated or -Gly-extended gastrins. The relevant standards (synthetic G34-GlyOH) were not available to us, but we tentatively identify the two peaks of L394 immunoreactivity as sulfated and unsulfated G34-GlyOH, on the basis of their immunochemical properties and similar retention times to G34. The concentration of G34-GlyOH in antral mucosa was estimated to be $<1 \%$ that of the amidated gastrins, i.e., of the order of $10 \mathrm{pmol} / \mathrm{g}$.

\section{Discussion}

The present study provides direct experimental evidence on the rates and routes of gastrin biosynthesis in antral mucosa. The

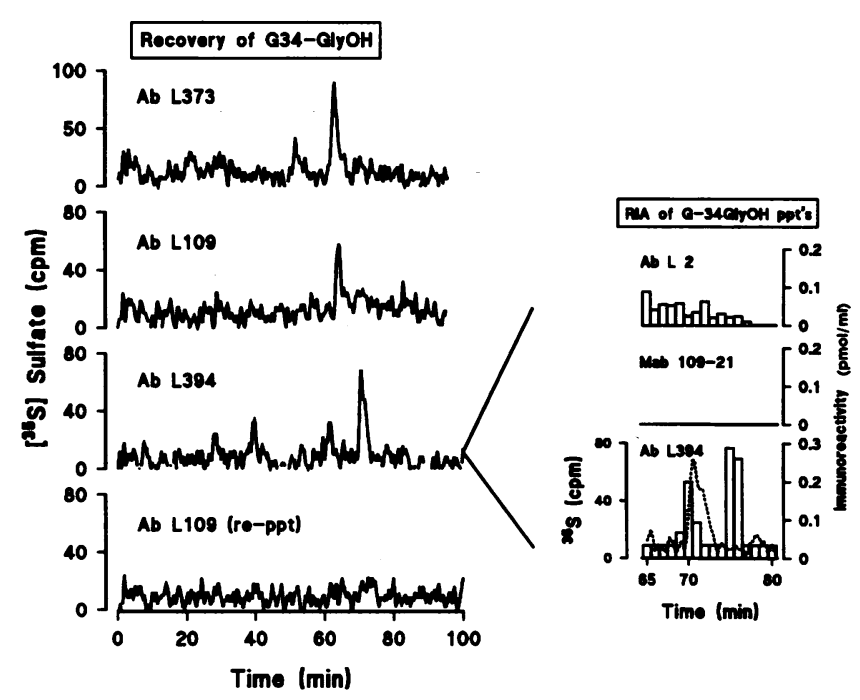

Figure 9. Identification of G34-GlyOH in a pulse-chase experiment. A sample obtained after a chase of $20 \mathrm{~min}$, following pulse labeling with $\left[{ }^{35}\right.$ S] sulfate (see Figs. 4 and 5) was sequentially precipitated (ppt) with antibodies L373 (to remove-Gly-extended gastrins), L109 (to remove amidated gastrin), and then divided into two equal parts. One part was precipitated with antibody L394 (raised to G9-GlyOH) and the other was reprecipitated (re-ppt) with antibody L109 (to verify the efficiency of the first precipitation). Left, shows the elution of labeled peptides. In these experiments, the starting conditions for column equilibration and sample application were $10 \%$ acetonitrile in $20 \mathrm{mM}$ Tris $\mathrm{pH} 7.4$; gradient elution from 10 to $25 \%$ acetonitrile was carried out over 80 min. Right, shows the results of radioimmunoassay of the HPLC eluates of L394 precipitates using three different antibodies (L2, specific for amidated gastrins; mAb 109-21, specific for -Gly-extended gastrins, and L394 reacting with -GlyOH peptides); for reference, the elution of ${ }^{35} \mathrm{~S}$-labeled material in the L394 precipitates has been superimposed (broken line, axis to left) on the radioimmunoassay data on the bottom right. The L394 precipitates contain material that elutes after G34-Gly and G34. The same material is identified in radioimmunoassay with antibody to -GlyOH gastrins, but not antibodies to amidated or -Gly gastrins. A second peak detected in radioimmunoassays has the properties predicted for unsulfated G34-GlyOH. In other experiments, reprecipitation with $\mathrm{L} 373$ was used in place of the second L109 precipitation: as with reprecipitation with $\mathrm{L} 109$, no further labeled material was recovered.

results indicate that the major acid-stimulating product, the heptadecapeptide $\mathrm{G17}$, is produced $\sim 2 \mathrm{~h}$ after mRNA translation and is generated from progastrin via G34-Gly, G34-GlyOH, and G34. There are at least three alternative routes by which the 59-93 sequence of progastrin, i.e., G34-Gly, might be processed (Fig. 10). The present data suggest that putative pathways in which G17-Gly and G17-GlyOH are intermediates in G17 synthesis, are unlikely to be of major importance. There are, however, substantial amounts of G17-Gly generated in rat antrum; the data suggest that this material should be regarded as an end product in its own right. This conclusion is interesting in the context of recent reports that-Gly-extended gastrins might have characteristic biological activities, notably stimulation of cell growth and of proton pump gene expression, independent of those of the amidated gastrins (12-14).

There is an extensive literature on the identification and chemical characterization of progastrin-derived peptides. All the major progastrin-derived peptides whose existence can be 


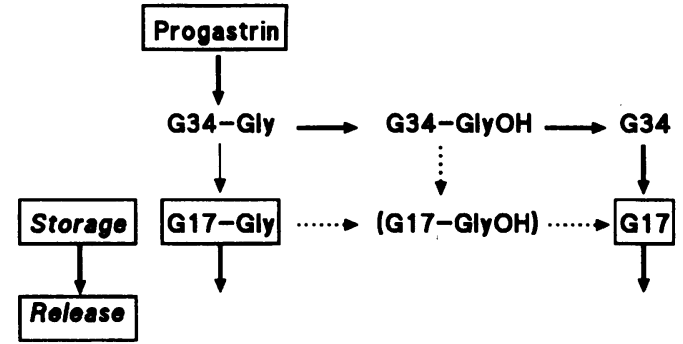

Figure 10. Schematic representation of the pathways by which progastrin is converted to G17. The present observations support the idea that the major pathway for synthesis of G17 is via G34-Gly, G34-GlyOH, and G34 (bold arrows). Although G17-Gly is produced the kinetic evidence does not support the idea of conversion to G17; neither do the data support the idea that G34-GlyOH is converted via G17-GlyOH to G17.

predicated from the gene sequence have now been isolated and chemically characterized $(4,5,19,22,26)$; variants differing in sulfation state at $\mathrm{Tyr}^{87}$ and phosphorylation state at $\mathrm{Ser}^{96}$ have also been defined together with many putative biosynthetic intermediates. However, little has been done to establish the biosynthetic pathways by which these molecules are linked. The idea that G34 might be a precursor of G17 was first suggested on the basis of identities in primary amino acid sequence and received support from the finding that the $\mathrm{NH}_{2}$ terminal tryptic fragment of G34 existed in a single population of cells in stoichiometric ratios with G17 (27). But the subsequent discovery of -Gly-extended variants of G17 suggested alternative biosynthetic routes $(16,17)$, for example that progastrin was first converted to G34-Gly, which was then cleaved to G17-Gly, followed by formation of G17. The present data do not support the latter scheme, but instead suggest that G34 is the main immediate precursor of G17.

The incorporation of $\left[{ }^{35} \mathrm{~S}\right]$ sulfate into amidated gastrins in rat antral mucosa was first described by Brand et al. (28). After $4 \mathrm{~h}$, incorporation of $\left[{ }^{35} \mathrm{~S}\right]$ sulfate and $\left[{ }^{3} \mathrm{H}\right]$ proline into $\mathrm{G} 34$ was observed, but there was only a minor peak of labeled G17. In similar experiments in the present study we found that labeled G17 was the major peak after $4 \mathrm{~h}$ incubation. The reasons for this difference are not known, but it is worth noting that to obtain detectable incorporation of label, Brand et al. increased gastrin synthesis by fundectomy, which may have influenced patterns of progastrin processing (28). There have been no previous studies of the kinetics of progastrin processing. We have found that the pool of progastrin present in the trans-Golgi network can be converted within minutes into G34-Gly. The time course of appearance of sulfated G34-Gly in pulse-chase experiments is similar to that for the disappearance of progastrin (21), suggesting relatively rapid cleavage at both $\mathrm{Arg}^{57}-\mathrm{Arg}^{58}$ and $\mathrm{Arg}^{94}-\mathrm{Arg}^{95}$, together with early removal of $\mathrm{COOH}$-terminal arginine residues. A proportion of the product, G34-Gly, is then converted to $\mathrm{G} 34$, and there is relatively slow cleavage at Lys $^{74}$-Lys ${ }^{75}$ of both G34 and G34-Gly to generate G17-Gly and G17. The time courses of appearance of labeled G17 and G17Gly were similar which suggests that the two peptides might be stored together in gastrin cells.

In keeping with the idea that amidated and -Gly-extended gastrins are costored in gastrin cells, it has been reported that in rat antral mucosa in vitro, and in humans and sheep in vivo, there is parallel secretion of amidated and -Gly-extended gastrins $(18,29,30)$. In the present study we examined the secretion of newly synthesized-amidated and -Gly-extended gastrins, by detection of labeled peptides in the media in pulse-chase experiments. Amidated and -Gly-extended gastrins were identified after a chase interval of $160 \mathrm{~min}$, which coincided with a decrease in the cellular content of the two groups of labeled peptide. Presumably at earlier periods in chase experiments, the biosynthetically labeled peptides were located in maturing secretory granules that are unavailable for exocytosis. It is interesting to note that the relative abundance of G17 and G34, and of G17-Gly and G34-Gly, were similar in cells and media after 160 min chase. The observation that labeled -Gly-extended and amidated gastrins are secreted in parallel provides direct support for the idea that both groups of peptides should be regarded as mature secretory products of the G-cell.

The enzyme PAM, which converts -Gly-extended peptides to the corresponding COOH-terminal amide, possesses two catalytic domains (15). The hydroxylating activity is responsible for the production of -GlyOH intermediates, and a lyase activity then converts this to the $\mathrm{COOH}$-terminal amide. The latter conversion can occur spontaneously at alkaline $\mathrm{pH}$ and is accelerated by warming; however, in the relatively acidic conditions of the secretory granule, the spontaneous conversion is unlikely to be physiologically important (31). We sought the putative-GlyOH intermediate using an antibody that reacts with this molecular species, although it also reacts with amidated and -Gly-extended gastrins. After taking steps to exclude the latter peptides, we have identified a newly synthesized gastrin that has properties compatible with those of G34-GlyOH, and so provides support for the proposed route from G34-Gly to G34. We have not, as yet, been able to detect material corresponding to G17-GlyOH. Further work will be needed to determine why PAM in gastrin cells appears to show preference for the conversion of G34-Gly to G34, over that of G17-Gly to G17. There is clear evidence that final production of amidated peptides occurs in secretory granules $(21,32)$. One possibility is that the progressive maturation of secretory granules leads to conditions, e.g., low intragranular $\mathrm{pH}$ (31), that are unfavorable for the PAM-hydroxylating activity. The present data suggest that such a change might occur 40-80 min after progastrin leaves the trans-Golgi network, and thereafter that either G34Gly or G34 is an acceptable substrate for cleavage at Lys ${ }^{74}$. $\mathrm{Lys}^{75}$ generating the corresponding $\mathrm{COOH}$-terminal hepta- or octadecapeptide.

The processing of progastrin varies considerably between cell types. In antral gastrin cells of the commonly studied mammalian species, including humans, G17 is a major product. However, in other cells, e.g., the human duodenum, there are higher relative concentrations of G34 (33-35), and in pituitary there are high relative concentrations of Gly-extended gastrins (36). In this context it is interesting that some tumors, e.g., colorectal carcinomas are now recognized to express the gastrin gene, albeit at low levels $(37-40)$. These cells do not contain more than trace amounts of mature amidated gastrins, but several laboratories have reported that the occurrence in tumor extracts of biosynthetic intermediates including -Gly-extended gastrins $(39,41,42)$. The potential autocrine or paracrine trophic activity of such peptides is plainly of interest. Elucidation of the mechanisms that determine the production of G17-Gly and G17 in antral gastrin cells may therefore be relevant in 
attempting to understand how processing is disrupted in tumor cells.

\section{Acknowledgments}

We are grateful to Dr. J. H. Walsh for the gift of antibody 109-21 and to Professor R. Ramage, Fellows of the Royal Society for the synthesis of -Gly and -GlyOH gastrin analogs.

This work was supported by grants from the Wellcome Trust and the Medical Research Council.

\section{References}

1. Docherty, K., and D. F. Steiner. 1982. Post-translational proteolysis in polypeptide hormone biosynthesis. Annu. Rev. Physiol. 44:625-638.

2. Mains, R. E., I. M. Dickerson, V. May, D. A. Stoffers, S. N. Perkins, L. H Quafik, E. J. Husten, and B. A. Eipper. 1990. Cellular and molecular aspects of peptide hormone biosynthesis. Front. Neuroendocrinol. 11:52-89.

3. Dockray, G. J., and A. Varro. 1993. Posttranslational processing. In Gastrin. J. H. Walsh, editor. Raven Press Ltd., New York. 33-46.

4. Gregory, R. A., and H. J. Tracy. 1964. The constitution and properties of two gastrins extracted from hog antral mucosa. Gut. 5:103-114.

5. Gregory, R. A., and H. J. Tracy. 1972. Isolation of two "big gastrins" from Zollinger-Ellison tumour tissue. Lancet. ii:797-799.

6. Dockray, G. J., and R. A. Gregory. 1989. Gastrin. In The Gastrointestinal System II. G. M. Makhlouf, editor. American Physiological Society, Bethesda, MD. 311-336.

7. Walsh, J. H. 1994. Gastrin. In Gut Peptides. J. H. Walsh and G. J. Dockray, editors. Raven Press Ltd., New York. 75-121.

8. Walsh, J. H., H. T. Debas, and M. I. Grossman. 1974. Pure human big gastrin: immunochemical properties, disappearance half time, and acid stimulating action in dogs. J. Clin. Invest. 54:477-485.

9. Walsh, J. H., J. I. Isenberg, J. Ansfield, and V. Maxwell. 1976. Clearance and acid-stimulating action of human big and little gastrins in duodenal ulcer subjects. J. Clin. Invest. 57:1125-1131.

10. Eysselein, V. E., V. Maxwell, T. Reedy, E. Wunsch, and J. H. Walsh. 1984. Similar acid stimulatory potencies of synthetic human big and little gastrins in man. J. Clin. Invest. 73:1284-1290.

11. Lamers, C. B., J. H. Walsh, J. B. Jansen, A. R. Harrison, A. F. Ippoliti, and J. H. van Tongeren. 1982. Evidence that gastrin 34 is preferentially released from the human duodenum. Gastroenterology. 83:233-239.

12. Seva, C., C. J. Dickinson, and T. Yamada. 1994. Growth-promoting effects of glycine-extended progastrin. Science (Wash. DC). 265:410-412.

13. Negre, F., P. Fagot-Revurat, N. Vaysse, J. F. Rehfeld, and L. Pradayrol. 1994. Progastrin induces autocrine/intracrine proliferative effects on pancreatic rat tumoral cells (AR4-2J). Gastroenterology. 106:309a. (Abstr.)

14. Kaise, M., A. Muraoka, H. Takeda, and T. Yamada. 1994. Glycineextended progastrin processing intermediates induce $\mathrm{H}+, \mathrm{K}+$-ATPase $\alpha$ subunit gene expression. Gastroenterology. 106:818a. (Abstr.)

15. Eipper, B. A., S. L. Milgram, E. J. Husten, H. Y. Yun, and R. E. Mains. 1993. Peptidylglycine $\alpha$-amidating monooxygenase: a multifunctional protein with catalytic processing, and routing domains. Protein Science. 2:489-497.

16. Sugano, K., G. W. Aponte, and T. Yamada. 1985. Identification and characterization of glycine-extended post-translational processing intermediates of progastrin in porcine stomach. J. Biol. Chem. 260:11724-11729.

17. Hilsted, L., and J. F. Rehfeld. 1987. $\alpha$-carboxyamidation of antral progastrin: relation to other post-translational modifications. J. Biol. Chem. 262:1695316957.

18. Azuma, T., R. T. Taggart, and J. H. Walsh. 1987. Effects of bombesin on the release of glycine-extended progastrin (gastrin $G$ ) in rat antral tissue culture Gastroenterology. 93:322-329.

19. Huebner, V. D., R. Jiang, T. D. Lee, K. Legesse, J. H. Walsh, J. E. Shively, P. Chew, T. Azumi, and J. R. Reeve. 1991. Purification and structural characterization of progastrin-derived peptides from a human gastrinoma. J. Biol. Chem. 266:12223-12227.
20. Varro, A., and G. J. Dockray. 1993. Post-translational processing of progastrin: inhibition of cleavage, phosphorylation and sulphation by brefeldin $\mathrm{A}$ Biochem. J. 295:813-819.

21. Varro, A., J. Henry, C. Vaillant, and G. J. Dockray. 1994. Discrimination between temperature- and brefeldin A-sensitive steps in the sulfation, phosphorylation, and cleavage of progastrin and its derivatives. J. Biol. Chem. 269:2076420770.

22. Dockray, G. J., A. Varro, H. Desmond, J. Young, H. Gregory, and R. A. Gregory. 1987. Post-translational processing of the porcine gastrin precursor by phosphorylation of the COOH-terminal fragment. J. Biol. Chem. 262:8643-8647.

23. Varro, A., J. Nemeth, J. Bridson, C. Lee, S. Moore, and G. J. Dockray. 1990. Processing of the gastrin precursor: modulation of phosphorylated, sulfated and amidated products. J. Biol. Chem. 265:21476-21481.

24. Dockray, G. J., R. G. Williams, and W. Y. Zhu. 1981. Development of region-specific antisera for the C-terminal tetrapeptide of gastrin/gastrin-cholecystokinin and their use in studies of immunoreactive forms of cholecystokinin in rat brain. Neurochem. Int. 3:281-288.

25. Dockray, G. J., L. Best, and I. L. Taylor. 1977. Immunochemical characterization of gastrin in pancreatic islets of normal and genetically obese mice. $J$. Endocrinol. 72:143-151.

26. Varro, A., H. Desmond, S. Pauwels, H. Gregory, J. Young, and G. J. Dockray. 1988. The human gastrin precursor: characterization of phosphorylated forms and fragments. Biochem. J. 256:951-957.

27. Dockray, G. J., C. Vaillant, and C. R. Hopkins. 1978. Biosynthetic relationships of big and little gastrins. Nature (Lond.). 273:770-772.

28. Brand, S. J., J. Klarlund, T. W. Schwartz, and J. F. Rehfeld. 1984. Biosynthesis of tyrosine O-sulfated gastrins in rat antral mucosa. J. Biol. Chem. 259:13246-13252.

29. Sugano, K., J. Park, W. O. Dobbins, and T. Yamada. 1987. Glycineextended progastrin processing intermediates:accumulation and cosecretion with gastrin. Am. J. Physiol. 253:G502-G507.

30. Ciccotosto, G. D., and A. Shulkes. 1992. Pharmacokinetics and organ specific metabolism of glycine-extended and amidated gastrin in sheep. Am. J. Physiol. 263:G802-G809.

31. Mellman, I., R. Fuchs, and A. Helenius. 1994. Acidification of the endocytic and exocytic pathways. Annu. Rev. Biochem. 55:663-700.

32. Rahier, J., S. Pauwels, and G. J. Dockray. 1987. Biosynthesis of gastrin: localization of the precursor and peptide products using electron microscopicimmunogold methods. Gastroenterology. 92:1146-1152.

33. Berson, S. A., and R. S. Yalow. 1971. Nature of immunoreactive gastrin extracted from tissues of gastrointestinal tract. Gastroenterology. 60:215-222.

34. Malmstrom, J., F. Stadil, and J. F. Rehfeld. 1976. Gastrins in tissue: concentration and component pattern in gastric, duodenal, and jejunal mucosa of normal human subjects and patients with duodenal ulcer. Gastroenterology. 70:697-703.

35. Calam, J., G. J. Dockray, R. Walker, H. J. Tracy, and D. Owens. 1980 Molecular forms of gastrin in peptic ulcer: comparison of serum and tissue concentrations of G17 and G34 in gastric and duodenal ulcer subjects. Eur. J. Clin. Invest. 10:241-247.

36. Rehfeld, J. F. 1988. The expression of progastrin, procholecystokinin and their hormonal products in pituitary cells. J. Mol. Endocrinol. 1:87-94.

37. Baldwin, G. S., A. Casey, T. Mantamadiotis, K. McBride, A. M. Sizeland, and C. M. Thumwood. 1990. PCR cloning and sequence of gastrin mRNA from carcinoma cell lines. Biochem. Biophys. Res. Commun. 170:691-697.

38. Baldwin, G. S., and Q. X. Zhang. 1992. Measurement of gastrin and transforming growth factor $\alpha$ messenger RNA levels in colonic carcinoma cell lines by quantitative polymerase chain reaction. Cancer Res. 52:2261-2267.

39. van Solinge, W. W., F. C. Nielsen, L. Friis-Hansen, U. G. Falkmer, and J. F. Rehfeld. 1993. Expression but incomplete maturation of progastrin in colorectal carcinomas. Gastroenterology. 104:1099-1107.

40. Finley, G. G., R. A. Koski, M. F. Melhem, J. M. Pipas, and A. I. Meisler 1993. Expression of the gastrin gene in the normal human colon and colorectal adenocarcinoma. Cancer Res. 53:2919-2926.

41. Nemeth, J., B. Taylor, S. Pauwels, A. Varro, and G. J. Dockray. 1993. Identification of progastrin derived peptides in colorectal carcinoma extracts. Gut. 34:90-95.

42. Kochman, M. L., J. Delvalle, C. J. Dickinson, and C. R. Boland. 1992. Post-translational processing of gastrin in neoplastic human colonic tissue. Biochem. Biophys. Res. Commun. 189:1165-1169. 